\title{
Impact of Primary Care Patient Visits on Racial and Ethnic Disparities in Preventive Care in the United States
}

\author{
Kevin Fiscella, MD, MPH, and Kathleen Holt, PhD
}

Background: The causes of racial and ethnic disparities in preventive care are not fully understood. We examined the hypothesis that fewer primary care visits by minority patients contribute to these disparities.

Methods: We analyzed claims for Medicare beneficiaries 65 and older who participated in the Medicare Current Beneficiary Survey, 1998 to 2002. Five preventive services were included: colorectal cancer testing, influenza vaccination, lipid screening, mammography, and Papanicolaou smear screening. In separate multivariate analyses, we examined the effect of minority status (self-report of African American race or Hispanic ethnicity) on having a claim in the past 12 months for each preventive service after successive control for number of primary care visits and other patient characteristics.

Results: The final sample included 15,962 subjects. In age-adjusted analyses, minorities had statistically lower rates of claims for each of the 5 procedures. After controlling for number of primary care visits, the effect of minority status was slightly attenuated but remained statistically significant for receipt of each procedure. After adding low income, low educational level and supplementary insurance, health status, and year, minority status was significantly associated only with colorectal cancer screening (odds ratio $[\mathrm{OR}] 0.79 ; 95 \%$ confidence interval $[\mathrm{CI}] 0.67$ to 0.94$)$ and influenza vaccinations (OR 0.56 ; 95\% CI 0.49 to 0.64).

Conclusions: The frequency of primary care visits seems to contribute minimally to racial and ethnic disparities in preventive services. Other patient characteristics, particularly those associated with poverty, explain much of these disparities. (J Am Board Fam Med 2007;20:587-597.)

Racial and ethnic disparities in preventive services have been widely documented, particularly for African American and Hispanic patients, ${ }^{1-9}$ but causes of these disparities remain incompletely understood. When disparities have been examined for specific visits, relatively few disparities in preventive care are observed. ${ }^{10-14}$ One potential explanation is that number of primary care visits mediates disparities in preventive care.

This article was externally peer reviewed.

Submitted 23 February 2007; revised 27 April 2007; accepted 3 May 2007.

From the Departments of Family Medicine $(\mathrm{KF}, \mathrm{KH})$ and Community and Preventive Medicine (KF), University of Rochester School of Medicine and Dentistry, Rochester, NY.

Funding: This project was supported by the Agency for Healthcare Research and Quality grant R01 HS 01317301A1

Conflict of interest: none declared.

Corresponding author: Kevin Fiscella, Departments of Family Medicine and Community and Preventive Medicine, University of Rochester School of Medicine and Dentistry, 1381 South Ave, Rochester, NY 14620 (E-mail: Kevin_Fiscella@urmc.rochester.edu).
In general, African Americans and Hispanic patients have fewer primary care visits, ${ }^{15,16}$ and fewer primary care visits are associated with lower rates of preventive care. ${ }^{17-20}$ If fewer primary care visits by minority patients largely mediate these disparities, then interventions designed to increase the number of primary care visits for these underserved patients might significantly ameliorate disparities in preventive services.

We examined this hypothesis using a nationally representative sample of elderly Medicare beneficiaries. We examined the independent association of minority status with receipt of colorectal cancer testing, influenza vaccination, lipid testing, mammography, and Papanicolaou smear testing. Next, we examined the impact of the frequency of primary care visits on this relationship. Last, we examined the impact of other potential barriers to care including differences in patient educational level, income, supplemental insurance, and health status on the association between minority status and receipt of preventive services. 


\section{Methods}

\section{Data Sources}

The study was approved by the University of Rochester Human Subjects Review Board. Our data source was the Centers for Medicare \& Medicaid Services' (CMS) Medicare Current Beneficiary Survey (MCBS). The MCBS includes an annual survey (for a maximum of 4 years per participant) of a rotating panel of Medicare beneficiaries. Participants are asked to provide sociodemographic, health status, and health care information. These data can be linked to each participant's Medicare claims data (diagnoses and diagnostic and procedural medical services) using linkages provided by CMS. This linkage at the patient level allows for creation of a unique dataset that includes a combination of detailed self-reported data and claims data. Further details about the survey are available at www.cms.hhs.gov/mcbs. Selected Medicare subpopulations are oversampled, and appropriate longitudinal and cross-sectional weights are provided to allow for estimates for the entire Medicare pop-

Table 1. Characteristics of a National Sample of Elderly, Community-Dwelling, non-HMO, Medicare Beneficiaries*

\begin{tabular}{|c|c|c|c|}
\hline Characteristics & $\begin{array}{l}\text { Minority } \\
(\mathrm{n}=2187)\end{array}$ & $\begin{array}{c}\text { White } \\
(\mathrm{n}=13,775)\end{array}$ & $\begin{array}{c}P \text { Value } \\
\text { (for } \chi^{2} \text { or } t \text { test) }\end{array}$ \\
\hline Age & & & $<.0001$ \\
\hline 65 to 69 & 25.0 & 20.2 & \\
\hline 70 to 74 & 21.7 & 21.8 & \\
\hline 75 to 79 & 19.7 & 21.7 & \\
\hline 80 to 84 & 15.6 & 20.3 & \\
\hline $85+$ & 18.1 & 15.9 & \\
\hline Sex & & & $<.0001$ \\
\hline Male & 38.4 & 43.4 & \\
\hline Female & 61.6 & 56.7 & \\
\hline Education & & & $<.0001$ \\
\hline Less than high school graduate & 61.9 & 28.8 & \\
\hline At least high school graduate & 38.1 & 71.2 & \\
\hline Metropolitan area & & & $<.0001$ \\
\hline No & 23.5 & 32.9 & \\
\hline Yes & 76.5 & 67.1 & \\
\hline Income & & & $<.0001$ \\
\hline$\leq 25,000$ annual & 85.4 & 57.6 & \\
\hline$>25,000$ annual & 14.6 & 42.4 & \\
\hline Lives alone & & & $<.1585$ \\
\hline No & 67.1 & 65.6 & \\
\hline Yes & 32.9 & 34.4 & \\
\hline Proxy responded & & & $<.0001$ \\
\hline No & 84.6 & 92.2 & \\
\hline Yes & 15.4 & 7.9 & \\
\hline Supplemental insurance & & & $<.0001$ \\
\hline None & 23.1 & 12.8 & \\
\hline Medicaid & 35.5 & 6.1 & \\
\hline Private insurance & 41.4 & 81.1 & \\
\hline Number of primary care office visits & & & $<.0001$ \\
\hline None & 36.7 & 28.9 & \\
\hline 1 to 2 & 20.5 & 26.8 & \\
\hline 3 or more & 42.8 & 44.3 & \\
\hline Activities of Daily Living $†$ & 1.8 & 1.6 & $<.0001$ \\
\hline Self-assessed health statusł & 3.1 & 2.7 & $<.0001$ \\
\hline
\end{tabular}

*Data derived from Medicare Current Beneficiary Survey (Access to Care), 1998 to 2002.

† On a 3-point scale, with higher scores indicating more impairment.

$\neq$ On a 5 -point scale, with higher scores indicating poorer health. 


\begin{tabular}{|c|c|c|c|c|c|}
\hline \multirow[b]{2}{*}{ Covariates Included in Models } & \multicolumn{5}{|c|}{ Odds Ratios for Claim for a Preventive Care Service by Minority Status } \\
\hline & $\begin{array}{l}\text { Colon Cancer } \\
\text { Screening }\end{array}$ & $\begin{array}{l}\text { Influenza } \\
\text { Vaccination }\end{array}$ & $\begin{array}{l}\text { Lipid } \\
\text { Screening }\end{array}$ & Mammogram & $\begin{array}{l}\text { Pap } \\
\text { Smear }\end{array}$ \\
\hline Age & $0.59(0.51-0.69)$ & $0.50(0.44-0.56)$ & $0.81(0.72-0.91)$ & $0.59(0.51-0.68)$ & $0.61(0.5-0.75)$ \\
\hline Age, frequency of primary care visits & $0.63(0.53-0.72)$ & $0.51(0.45-0.57)$ & $0.86(0.76-0.97)$ & $0.61(0.53-0.7)$ & $0.64(0.52-0.79)$ \\
\hline $\begin{array}{l}\text { Age, frequency of primary care visits, } \\
\text { education level }\end{array}$ & $0.69(0.59-0.81)$ & $0.54(0.47-0.6)$ & $0.92(0.81-1.04)$ & $0.71(0.61-0.81)$ & $0.76(0.62-0.94)$ \\
\hline All covariates (listed in Table 1) & $0.79(0.67-0.94)$ & $0.56(0.49-0.64)$ & $0.95(0.84-1.08)$ & $0.9(0.77-1.05)$ & $0.94(0.76-1.17)$ \\
\hline
\end{tabular}

Data are expressed as odds ratio (95\% confidence interval).

ulation. To maximize sample size, data were aggregated across 4 years (1998 to 2002). The total number of observations initially available for analysis was 88,509 .

\section{Exclusion Criteria}

Our study sample consisted of whites, African Americans, and Hispanics over 65 years of age. Respondents were excluded from our sample for any of the following reasons (number in parentheses refer to the number of excluded participants): (1) residence in a long-term care facility because care is often provided within the facility $(6,462)$; (2) age less than 65 years-only persons with endstage renal disease or qualifying disabilities are eligible for Medicare for this age-group (12,852); (3) race/ethnicity other than Hispanic, African American/black, or white because the focus of the study was on these 2 minority groups and sample size for other groups were considerably smaller $(3,169)$; (4) enrollment in a Medicare HMO and hence had no claims from their medical visits $(15,262)$; or (5) lacked Medicare B and thus did not have ambulatory claims $(1,118)$.

To minimize bias associated with multiple repetitions of the survey, we randomly selected among years of the survey for those respondents who participated in multiple years of data collection, eliminating 25,834 repeated observations. Finally, we eliminated respondents with missing data on any of the covariates $(7,850)$. The final sample contained 13,775 non-Hispanic white and 2187 minority (for analytic purposes, we classified the African American and Hispanic participants as minority) patients.

\section{Measures}

\section{Race/Ethnicity}

Minority status was defined as self-report of African American/black race or Hispanic ethnicity based on the responses to 2 questions: "(Are you/Is $\mathrm{SP})$ of Hispanic or Latino origin?" [Yes or No] and "Looking at this card, what is (your/SP's) race?" [American Indian or Alaska Native; Asian; black or African American; Native Hawaiian or other Pacific Islander; white; another race (specify)]. Participants in our analyses were classified as a minority if they responded either "yes" to the first question or "black or African American" to the second question. Other minorities were excluded because of small numbers and heterogeneity.

\section{Receipt of Clinical Preventive Services}

Relevant Current Procedural Terminology (CPT), Healthcare Common Procedure Coding (HCPC), and Berenson-Eggers Type of Service (BETOS) codes were used to identify persons receiving preventive services during 1 year of their survey participation. Details of this identification have been previously provided..$^{21}$ Because of the challenges in distinguishing screening procedures from diagnostic procedures, ${ }^{22}$ both screening and diagnostic codes were included.

\section{Primary Care Visits}

For each selected respondent, we examined the claims records generated during the MCBS survey year. All claims coded as bills from physicians describing themselves as general practitioners, family physicians, internists, obstetrician/gynecologists, or geriatricians were counted. The frequency distributions by procedure were skewed, with a mean of around 5 visits during the year across all the procedures. Close examination of these distributions by each preventive service revealed approximately $30 \%$ of the sample having no primary care visits during the year, $25 \%$ having 1 to 2 visits, and $45 \%$ having 3 or more visits. We categorized "primary care visit number" using these cut-offs and 


\begin{tabular}{|c|c|c|c|}
\hline Patient Characteristic & $\begin{array}{l}\text { Odds } \\
\text { Ratio }\end{array}$ & $\begin{array}{l}\text { Lower } 95 \% \\
\text { Confidence } \\
\text { Interval }\end{array}$ & $\begin{array}{c}\text { Upper 95\% } \\
\text { Confidence } \\
\text { Interval }\end{array}$ \\
\hline \multicolumn{4}{|c|}{ Race or ethnicity (referent: non-Hispanic white) } \\
\hline Minority & 0.79 & 0.67 & 0.94 \\
\hline \multicolumn{4}{|l|}{ Age (referent: $\geq 85$ years) } \\
\hline 65 to 69 & 1.29 & 1.13 & 1.48 \\
\hline 70 to 74 & 1.33 & 1.17 & 1.52 \\
\hline 75 to 79 & 1.44 & 1.27 & 1.62 \\
\hline 80 to 84 & 1.18 & 1.03 & 1.35 \\
\hline \multicolumn{4}{|l|}{ Educational attainment } \\
\hline Less than high school & 0.84 & 0.76 & 0.93 \\
\hline \multicolumn{4}{|c|}{ Residence (referent: nonmetropolitan residence) } \\
\hline Metropolitan area & 1.12 & 1.00 & 1.25 \\
\hline \multicolumn{4}{|c|}{ Income (referent: $<\$ 25,000)$} \\
\hline$\leq \$ 25,000$ & 0.80 & 0.73 & 0.88 \\
\hline \multicolumn{4}{|c|}{ Functional health (3-point scale) } \\
\hline 1 point decrease & 0.89 & 0.85 & 0.94 \\
\hline \multicolumn{4}{|c|}{ Self-rated health (5-point scale) } \\
\hline 1 point decrease & 0.99 & 0.95 & 1.04 \\
\hline \multicolumn{4}{|c|}{ Living situation (referent: married or cohabitating) } \\
\hline Lives alone & 1.06 & 0.96 & 1.16 \\
\hline \multicolumn{4}{|c|}{ Respondent (referent: participant) } \\
\hline Proxy & 0.79 & 0.66 & 0.95 \\
\hline \multicolumn{4}{|c|}{ Supplemental insurance (referent: private) } \\
\hline None & 0.58 & 0.50 & 0.68 \\
\hline Medicaid & 0.77 & 0.65 & 0.92 \\
\hline \multicolumn{4}{|l|}{ Survey year (referent: 4) } \\
\hline 1 & 0.76 & 0.69 & 0.85 \\
\hline 2 & 1.15 & 1.01 & 1.31 \\
\hline 3 & 1.02 & 0.87 & 1.18 \\
\hline \multicolumn{4}{|c|}{ Number of primary care office visits (referent: none) } \\
\hline 1 to 2 & 2.31 & 1.99 & 2.68 \\
\hline 3 or more & 3.33 & 2.85 & 3.90 \\
\hline \multicolumn{4}{|l|}{ Sex (referent: male) } \\
\hline Female & 1.07 & 0.98 & 1.17 \\
\hline
\end{tabular}

ran models with and without this variable included to assess the extent to which visit frequency mediated the association between race/ethnicity and receipt of preventive services.

\section{Covariates}

We controlled for the following covariates in our analyses: age (categorized as 65 to 69,70 to 74,75 to 79,80 to 84 , and with 85 and older as the reference group), education (less than high school graduation versus at least high school graduation), annual income (less than $\$ 25,000$ versus $\$ 25,000$ or more), metropolitan residence (versus not), whether the respondent lived alone (versus not), availability of supplemental insurance (private insurance, Medicaid supplemental, versus none), proxy response to the survey (versus self-response), functional status using the Activities of Daily Living scale (a 3-point impairment scale), ${ }^{23}$ and respondents' estimates of their general health compared with others of their age (5-point scale). Such relative self-ratings of health status have been shown to predict mortality. ${ }^{24,25}$

\section{Statistical Analyses}

To accommodate the complex survey design of the MCBS, including the multiple years of enrollment in the survey and clustered sampling, SAS SUR- 


\begin{tabular}{|c|c|c|c|}
\hline Patient Characteristic & $\begin{array}{l}\text { Odds } \\
\text { Ratio }\end{array}$ & $\begin{array}{l}\text { Lower 95\% } \\
\text { Confidence } \\
\text { Interval }\end{array}$ & $\begin{array}{c}\text { Upper } 95 \% \\
\text { Confidence } \\
\text { Interval }\end{array}$ \\
\hline \multicolumn{4}{|c|}{ Race or ethnicity (referent: non-Hispanic white) } \\
\hline Minority & 0.56 & 0.49 & 0.64 \\
\hline \multicolumn{4}{|l|}{ Age (referent: $\geq 85$ years) } \\
\hline 65 to 69 & 0.69 & 0.58 & 0.82 \\
\hline 70 to 74 & 0.93 & 0.82 & 1.07 \\
\hline 75 to 79 & 1.07 & 0.94 & 1.21 \\
\hline 80 to 84 & 1.11 & 0.97 & 1.26 \\
\hline \multicolumn{4}{|c|}{$\begin{array}{l}\text { Educational attainment (referent: at least high } \\
\text { school) }\end{array}$} \\
\hline Less than high school & 0.93 & 0.85 & 1.02 \\
\hline \multicolumn{4}{|c|}{ Residence (referent: nonmetropolitan residence) } \\
\hline Metropolitan area & 0.88 & 0.76 & 1.02 \\
\hline \multicolumn{4}{|c|}{ Income (referent: $>\$ 25,000)$} \\
\hline$\leq \$ 25,000$ & 0.81 & 0.73 & 0.90 \\
\hline \multicolumn{4}{|c|}{ Functional health (3-point scale) } \\
\hline 1 point decrease & 0.96 & 0.91 & 1.02 \\
\hline \multicolumn{4}{|c|}{ Self-rated health (5-point scale) } \\
\hline 1 point decrease & 1.00 & 0.96 & 1.05 \\
\hline \multicolumn{4}{|c|}{$\begin{array}{l}\text { Living situation (referent: married or } \\
\text { cohabitating) }\end{array}$} \\
\hline Lives alone & 1.11 & 1.02 & 1.21 \\
\hline \multicolumn{4}{|c|}{ Respondent (referent: participant) } \\
\hline Proxy & 0.90 & 0.76 & 1.07 \\
\hline \multicolumn{4}{|c|}{ Supplemental insurance (referent: private) } \\
\hline None & 0.58 & 0.51 & 0.67 \\
\hline Medicaid & 0.78 & 0.65 & 0.94 \\
\hline \multicolumn{4}{|l|}{ Survey year (referent: 4) } \\
\hline 1 & 0.13 & 0.11 & 0.15 \\
\hline 2 & 1.04 & 0.93 & 1.17 \\
\hline 3 & 1.09 & 0.97 & 1.22 \\
\hline \multicolumn{4}{|c|}{$\begin{array}{l}\text { Number of primary care office visits (referent: } \\
\text { none) }\end{array}$} \\
\hline 1 to 2 & 1.92 & 1.68 & 2.19 \\
\hline 3 or more & 2.96 & 2.61 & 3.35 \\
\hline \multicolumn{4}{|l|}{ Sex (referent: male) } \\
\hline Female & 1.05 & 0.95 & 1.15 \\
\hline
\end{tabular}

VEY procedures were used (SAS Institute, Cary, NC; Version 9.1). Survey weights were used to adjust for oversampling and nonresponse to yield population parameter estimates. Data were analyzed with logistic regression to assess the adjusted relationship between minority status and receipt of a preventive service.

\section{Results}

Table 1 summarizes the characteristics of the sample based on minority status. In general, minority participants had lower income, less education, poorer health and functional status, fewer visits, and were less likely to receive preventive services than non-Hispanic whites.

The multivariate analyses are shown in Table 2. The first row presents results that adjust for age and control for sampling design and national weights. In each instance, minority patients had lower rates of preventive services in the past 12 months than non-Hispanic whites.

The second row in Table 2 adds to the model control for primary care visit frequency. Although adjustment for the number of primary 


\begin{tabular}{|c|c|c|c|}
\hline Patient Characteristic & $\begin{array}{l}\text { Odds } \\
\text { Ratio }\end{array}$ & $\begin{array}{c}\text { Lower } 95 \% \text { Confidence } \\
\text { Interval }\end{array}$ & $\begin{array}{c}\text { Upper } 95 \% \text { Confidence } \\
\text { Interval }\end{array}$ \\
\hline \multicolumn{4}{|c|}{ Race or ethnicity (referent: non-Hispanic white) } \\
\hline Minority & 0.95 & 0.84 & 1.08 \\
\hline \multicolumn{4}{|l|}{ Age (referent: $\geq 85$ years) } \\
\hline 65 to 69 & 1.71 & 1.51 & 1.95 \\
\hline 70 to 74 & 1.87 & 1.65 & 2.12 \\
\hline 75 to 79 & 1.68 & 1.50 & 1.89 \\
\hline 80 to 84 & 1.42 & 1.26 & 1.60 \\
\hline \multicolumn{4}{|c|}{ Educational attainment (referent: at least high school) } \\
\hline Less than high school & 0.91 & 0.83 & 0.99 \\
\hline \multicolumn{4}{|c|}{ Residence (referent: nonmetropolitan residence) } \\
\hline Metropolitan area & 1.17 & 1.00 & 1.36 \\
\hline \multicolumn{4}{|c|}{ Income (referent: $>\$ 25,000)$} \\
\hline$\leq \$ 25,000$ & 0.85 & 0.78 & 0.92 \\
\hline \multicolumn{4}{|c|}{ Functional health (3-point scale) } \\
\hline 1 point decrease & 0.91 & 0.87 & 0.94 \\
\hline \multicolumn{4}{|c|}{ Self-rated health (5-point scale) } \\
\hline 1 point decrease & 1.06 & 1.02 & 1.10 \\
\hline \multicolumn{4}{|c|}{ Living situation (referent: married or cohabitating) } \\
\hline Lives alone & 1.15 & 1.06 & 1.25 \\
\hline \multicolumn{4}{|c|}{ Respondent (referent: participant) } \\
\hline Proxy & 0.64 & 0.56 & 0.73 \\
\hline \multicolumn{4}{|c|}{ Supplemental insurance (referent: private) } \\
\hline None & 0.67 & 0.61 & 0.74 \\
\hline Medicaid & 1.06 & 0.93 & 1.21 \\
\hline \multicolumn{4}{|l|}{ Survey year (referent: 4) } \\
\hline 1 & 0.79 & 0.71 & 0.88 \\
\hline 2 & 1.05 & 0.93 & 1.18 \\
\hline 3 & 1.06 & 0.94 & 1.19 \\
\hline \multicolumn{4}{|c|}{ Number of primary care office visits (referent: none) } \\
\hline 1 to 2 & 2.56 & 2.29 & 2.85 \\
\hline At least 3 & 4.29 & 3.84 & 4.79 \\
\hline \multicolumn{4}{|l|}{ Sex (referent: male) } \\
\hline Female & 1.04 & 0.96 & 1.13 \\
\hline
\end{tabular}

care visits resulted in a slight and consistent increase in the odds of a minority patient receiving a clinical preventive service, the increase was not statistically significant. Notably, racial and ethnic disparities for each of the preventive service remained statistically significant.

The third row of Table 2 adds control for the effects of low educational attainment to the model. The association of minority race/ethnicity with lipid screening was no longer statistically significant. The final row adds control for the remaining covariates including low income, resulting in further attenuation of effects of minority race/ethnicity. The association remained statistically significant for only colorectal cancer screening and influenza vaccination (Tables 3 and 4). In each of these models containing all the covariates, frequency of primary care visits was strongly associated with receipt of preventive services (Tables 3-7). The odds ratio for 3 or more primary care visits ranged from 2.95 for mammogram to 6.90 for Papanicolaou smear.

\section{Discussion}

Consistent with previous studies, ${ }^{1-9}$ we found significant age-adjusted racial and ethnic disparities for receipt of preventive services in the past 12 months in this national sample of elderly patients. Despite poorer self-rated and functional 


\begin{tabular}{|c|c|c|c|}
\hline Patient Characteristic & $\begin{array}{l}\text { Odds } \\
\text { Ratio }\end{array}$ & $\begin{array}{l}\text { Lower } 95 \% \\
\text { Confidence } \\
\text { Interval }\end{array}$ & $\begin{array}{c}\text { Upper } 95 \% \\
\text { Confidence } \\
\text { Interval }\end{array}$ \\
\hline \multicolumn{4}{|c|}{ Race or ethnicity (referent: non-Hispanic white) } \\
\hline Minority & 0.90 & 0.77 & 1.05 \\
\hline \multicolumn{4}{|l|}{ Age (referent: $\geq 85$ years) } \\
\hline 65 to 69 & 3.40 & 2.74 & 4.21 \\
\hline 70 to 74 & 3.06 & 2.53 & 3.71 \\
\hline 75 to 79 & 2.68 & 2.20 & 3.26 \\
\hline 80 to 84 & 2.27 & 1.86 & 2.79 \\
\hline \multicolumn{4}{|c|}{ Educational attainment (referent: at least high school) } \\
\hline Less than high school & 0.78 & 0.70 & 0.88 \\
\hline \multicolumn{4}{|c|}{ Residence (referent: nonmetropolitan residence) } \\
\hline Metropolitan area & 0.96 & 0.80 & 1.15 \\
\hline \multicolumn{4}{|c|}{ Income (referent: $>\$ 25,000)$} \\
\hline$\leq \$ 25,000$ & 0.74 & 0.65 & 0.84 \\
\hline \multicolumn{4}{|c|}{ Functional health (3-point scale) } \\
\hline 1 point decrease & 0.86 & 0.82 & 0.91 \\
\hline \multicolumn{4}{|l|}{$\begin{array}{l}\text { Self-rated health } \\
\text { (5-point scale) }\end{array}$} \\
\hline 1 point decrease & 0.92 & 0.88 & 0.97 \\
\hline \multicolumn{4}{|c|}{ Living situation (referent: married or cohabitating) } \\
\hline Lives alone & 0.99 & 0.89 & 1.10 \\
\hline \multicolumn{4}{|c|}{ Respondent (referent: participant) } \\
\hline Proxy & 0.55 & 0.42 & 0.71 \\
\hline \multicolumn{4}{|c|}{ Supplemental insurance (referent: private) } \\
\hline None & 0.51 & 0.41 & 0.62 \\
\hline Medicaid & 0.75 & 0.62 & 0.90 \\
\hline \multicolumn{4}{|l|}{ Survey year (referent: 4) } \\
\hline 1 & 0.52 & 0.45 & 0.60 \\
\hline 2 & 0.89 & 0.76 & 1.05 \\
\hline 3 & 0.96 & 0.81 & 1.16 \\
\hline \multicolumn{4}{|c|}{ Number of primary care office visits (referent: none) } \\
\hline 1 to 2 & 2.41 & 1.99 & 2.91 \\
\hline At least 3 & 2.95 & 2.46 & 3.54 \\
\hline
\end{tabular}

health, minorities were significantly less likely to have made 2 to 3 primary care visits and more likely to have had no primary care visits during the year. However, when we assessed the impact of these disparities in primary care on disparities in preventive care, we found that primary care visit frequency only slightly attenuated these disparities.

Controlling for differences in low educational attainment resulted in further attenuation of minority effects. These findings are consistent with previous studies suggesting that disparities in education (and the closely related construct, health literacy) contribute to racial and ethnic disparities in preventive care. ${ }^{8,26-31}$ Controlling for other factors likely to af- fect care including low income, supplementary insurance, and health status eliminated the association between minority status and receipt of preventive services except for colorectal cancer screening and influenza vaccination. These findings are consistent with previous studies showing that minorities are less likely to receive colorectal cancer screening and influenza vaccination, even after controlling for various access barriers. ${ }^{4,5,32}$ The causes of these residual disparities may include unmeasured factors such as attitudes toward particular procedures, costs not fully covered by insurance, language, and health literacy. ${ }^{33-35}$

Our findings suggest that although frequency of primary care visits are in general strongly 


\begin{tabular}{|c|c|c|c|}
\hline Patient Characteristic & $\begin{array}{l}\text { Odds } \\
\text { Ratio }\end{array}$ & $\begin{array}{l}\text { Lower } 95 \% \\
\text { Confidence } \\
\text { Interval }\end{array}$ & $\begin{array}{c}\text { Upper 95\% } \\
\text { Confidence } \\
\text { Interval }\end{array}$ \\
\hline \multicolumn{4}{|c|}{ Race or ethnicity (referent: non-Hispanic white) } \\
\hline Minority & 0.94 & 0.76 & 1.17 \\
\hline \multicolumn{4}{|l|}{ Age (referent: $\geq 85$ years) } \\
\hline 65 to 69 & 4.39 & 3.43 & 5.61 \\
\hline 70 to 74 & 4.00 & 3.14 & 5.08 \\
\hline 75 to 79 & 2.90 & 2.23 & 3.77 \\
\hline 80 to 84 & 2.03 & 1.59 & 2.59 \\
\hline \multicolumn{4}{|c|}{ Educational attainment (referent: at least high school) } \\
\hline Less than high school & 0.76 & 0.66 & 0.88 \\
\hline \multicolumn{4}{|c|}{ Residence (referent: nonmetropolitan residence) } \\
\hline Metropolitan area & 1.14 & 0.96 & 1.35 \\
\hline \multicolumn{4}{|c|}{ Income (referent: $>\$ 25,000)$} \\
\hline$\leq \$ 25,000$ & 0.75 & 0.65 & 0.88 \\
\hline \multicolumn{4}{|c|}{ Functional health (3-point scale) } \\
\hline 1 point decrease & 0.90 & 0.84 & 0.97 \\
\hline \multicolumn{4}{|c|}{ Self-rated health (5-point scale) } \\
\hline 1 point decrease & 0.85 & 0.79 & 0.91 \\
\hline \multicolumn{4}{|c|}{ Living situation (referent: married or cohabitating) } \\
\hline Lives alone & 1.19 & 1.02 & 1.38 \\
\hline \multicolumn{4}{|c|}{ Respondent (referent: participant) } \\
\hline Proxy & 0.83 & 0.57 & 1.20 \\
\hline \multicolumn{4}{|c|}{ Supplemental insurance (referent: private) } \\
\hline None & 0.78 & 0.62 & 0.98 \\
\hline Medicaid & 0.69 & 0.53 & 0.89 \\
\hline \multicolumn{4}{|l|}{ Survey year (referent: 4) } \\
\hline 1 & 0.84 & 0.72 & 0.99 \\
\hline 2 & 1.01 & 0.85 & 1.21 \\
\hline 3 & 1.06 & 0.88 & 1.29 \\
\hline \multicolumn{4}{|c|}{ Number of primary care office visits (referent: none) } \\
\hline 1 to 2 & 4.55 & 3.53 & 5.87 \\
\hline At least 3 & 6.90 & 5.33 & 8.93 \\
\hline
\end{tabular}

linked to receipt of preventive services, they seem to contribute relatively little to racial and ethnic disparities in receipt of these services. Instead, socioeconomic characteristics associated with poverty such as low educational attainment and low income, in addition to availability of supplemental insurance and health status, explain much of these disparities and also contribute to fewer visits. It is quite possible that 15 -minute office visits $^{36}$ do not provide sufficient time for primary care physicians to address many of these interrelated barriers to care. ${ }^{37}$ Longer office visits are probably required when working with impoverished patients to confirm patient understanding ${ }^{38}$ and also to problem solve around how to best address financial barriers to adherence. ${ }^{39}$
Practice- and population-based interventions may help address racial and ethnic disparities in preventive services. Use of patient registries, combined with the ability to target patients overdue for a preventive service (regardless of whether they have a scheduled visit), improve uptake of preventive care. ${ }^{40,41}$ This strategy has been effective in promoting childhood immunizations and improving rates of cancer screenings in minority populations. ${ }^{42,43}$ Such recall systems typically require establishment of an electronic patient tracking registry in addition to personnel who can contract patients by mail or phone. ${ }^{44}$ Additional targeted and tailored interventions may be needed to address other mediators of disparities including financial barriers, health lit- 
eracy, and cultural beliefs and attitudes among others. Newer reimbursement models are needed that take into account the increased costs of caring for poor patients, ${ }^{45}$ to avoid the unintended consequences of pay-for-performance. ${ }^{46}$

These findings are subject to several limitations. First, the sample was confined to community-dwelling, Medicare beneficiaries aged 65 and older and those not enrolled in managed care. Thus, the extent to which these findings generalize to other groups cannot be assessed. Second, we used a broad definition of preventive services because these data do not allow us to clearly distinguish between screening or diagnostic tests. ${ }^{22}$ However, studies that have attempted to tease apart screening and diagnostic procedures also show disparities in screening. ${ }^{5} \mathrm{We}$ only examined visits to primary care physicians to include in our primary analyses. We did analyze our data using all physician visits (not just primary care visits), and the results were not appreciably different from the results described above. Third, we grouped visit frequency into 3 categories, potentially masking differences within these categories. In many cases, at least one visit with at least one visit with a primary physician would be required to receive the particular preventive service, so we included a category for no visits. We also conducted analyses using greater numbers of categories for visits ( 0,1 to 2,3 to 5,6 or more, 0,1 to 4,5 to 9,10 or more) in addition to using continuous measures. Results remained consistent with those presented above. Last, we could not determine, based on these data, whether any patient clearly satisfied the US Preventive Services Task Force screening recommendations because results from prior screening were not available. For example, Papanicolaou smear screening is not recommended past 65 years among women who have had adequate screening, normal Papanicolaou smears, and are not otherwise at high risk. But, we had no way of ascertaining this from these data. Similarly, we lacked 10 years of data for colonoscopy screening and results for colonoscopy. For these reasons, we assumed that receipt of the procedure in the last 12 months represented a proxy for preventive services screening regardless of the recommended interval. Finally, because African American patients have higher rates of colonic pol$\mathrm{yps}^{47}$ and cervical disease, ${ }^{48}$ our methods may have tended to underestimate the actual extent of disparities in receipt of screening.

In conclusion, this study shows that among elderly patients, fewer primary care visits by minorities are only one of many factors contributing to racial and ethnic disparities in preventive services. Thus, multipronged interventions will probably be required to address these disparities.

\section{References}

1. O'Malley AS, Forrest CB, Feng S, Mandelblatt J. Disparities despite coverage: gaps in colorectal cancer screening among Medicare beneficiaries. Arch Intern Med 2005;165:2129-35.

2. Felix-Aaron K, Moy E, Kang M, Patel M, Chesley FD, Clancy C. Variation in quality of men's health care by race/ethnicity and social class. Med Care 2005;43:172-81.

3. Swan J, Breen N, Coates RJ, Rimer BK, Lee NC. Progress in cancer screening practices in the United States: results from the 2000 National Health Interview Survey. Cancer 2003;97:1528-40.

4. Hebert PL, Frick KD, Kane RL, McBean AM. The causes of racial and ethnic differences in influenza vaccination rates among elderly Medicare beneficiaries. Health Serv Res 2005;40:517-38.

5. Cooper GS, Koroukian SM. Racial disparities in the use of and indications for colorectal procedures in Medicare beneficiaries. Cancer 2004;100:418-24.

6. Stewart SH, Silverstein MD. Racial and ethnic disparity in blood pressure and cholesterol measurement. J Gen Intern Med 2002;17:405-11.

7. Centers for Disease Control and Prevention (CDC). Access to health-care and preventive services among Hispanics and non-Hispanics-United States, 20012002. MMWR Morb Mortal Wkly Rep 2004;53: 937-41.

8. Sambamoorthi U, McAlpine DD. Racial, ethnic, socioeconomic, and access disparities in the use of preventive services among women. Prev Med 2003; 37:475-84.

9. Gilligan T, Wang PS, Levin R, Kantoff PW, Avorn J. Racial differences in screening for prostate cancer in the elderly. Arch Intern Med 2004;164:1858-64.

10. Franks P, Fiscella K, Meldrum S. Racial disparities in the content of primary care office visits. J Gen Intern Med 2005;20:599-603.

11. Fiscella K, Franks P. Does the content of primary care visits differ by the racial composition of physicians' practices? Am J Med 2006;119:348-53.

12. Asch SM, Kerr EA, Keesey J, et al. Who is at greatest risk for receiving poor-quality health care? N Engl J Med 2006;354:1147-56.

13. O'Malley AS, Forrest CB, Politzer RM, Wulu JT, Shi L. Health center trends, 1994-2001: what do 
they portend for the federal growth initiative? Health Aff 2005;24:465-72.

14. Ma J, Stafford RS. Quality of US outpatient care: temporal changes and racial/ethnic disparities. Arch Intern Med 2005;165:1354-61.

15. Forrest CB, Whelan EM. Primary care safety-net delivery sites in the United States: a comparison of community health centers, hospital outpatient departments, and physicians' offices. JAMA 2000;284: 2077-83.

16. Schappert SM, Burt CW. Ambulatory care visits to physician offices, hospital outpatient departments, and emergency departments: United States, 200102. Vital Health Stat 13: Data From the National Health Survey 2006;1-66.

17. Burns RB, McCarthy EP, Freund KM, et al. Black women receive less mammography even with similar use of primary care. Ann Intern Med 1996;125:17382.

18. Etzioni DA, Yano EM, Rubenstein LV, et al. Measuring the quality of colorectal cancer screening: the importance of follow-up. Dis Colon Rectum 2006; 49:1002-10.

19. Bindman AB, Grumbach K, Osmond D, Vranizan K, Stewart AL. Primary care and receipt of preventive services. J Gen Intern Med 1996;11:269-76.

20. Meissner HI, Breen N, Klabunde CN, Vernon SW. Patterns of colorectal cancer screening uptake among men and women in the United States. Cancer Epidemiol Biomarker Prev 2006;15:389-94.

21. Fiscella K, Holt K, Meldrum S, Franks P. Disparities in preventive procedures: comparisons of self report and Medicare claims data. BMC Health Serv Res 2006;6:122 [cited 26 April 2007]. Available from: http://www.biomedcentral.com/content/ pdf/1472-6963-6-122.pdf.

22. Freeman JL, Klabunde CN, Schussler N, Warren JL, Virnig BA, Cooper GS. Measuring breast, colorectal, and prostate cancer screening with Medicare claims data. Med Care 2002;40:36-42.

23. Katz S, Branch LG, Branson MH, Papsidero JA, Beck JC, Greer DS. Active life expectancy. N Engl J Med 1983;309:1218-24.

24. Grand A, Grosclaude P, Bocquet H, Pous J, Albarede JL. Disability, psychosocial factors and mortality among the elderly in a rural French population. J Clin Epidemiol 1990;43:773-82.

25. Manderbacka K, Kareholt I, Martikainen P, Lundberg $O$. The effect of point of reference on the association between self-rated health and mortality. Soc Sci Med 2003;56:1447-52.

26. Hoffman-Goetz L, Breen NL, Meissner H. The impact of social class on the use of cancer screening within three racial/ethnic groups in the United States. Ethnic Dis 1998;8:43-51.

27. Scott TL, Gazmararian JA, Williams MV, Baker DW. Health literacy and preventive health care use among Medicare enrollees in a managed care organization. Med Care 2002;40:395-404.

28. Garbers S, Chiasson MA. Inadequate functional health literacy in Spanish as a barrier to cervical cancer screening among immigrant Latinas in New York City. Prev Chron Dis 2004;1:A07.

29. Howard DH, Sentell T, Gazmararian JA. Impact of health literacy on socioeconomic and racial differences in health in an elderly population. J Gen Intern Med 2006;21:857-61.

30. Sudore RL, Mehta KM, Simonsick EM, et al. Limited literacy in older people and disparities in health and healthcare access. J Am Geriatr Soc 2006;54: 770-6.

31. Agency for Healthcare Research and Quality. National healthcare disparities report, 2006 [cited 26 April 2007]. Available at: http://www.ahrq.gov/qual/ nhdr06/nhdr06.htm.

32. Rangel MC, Shoenbach VJ, Weigle KA, Hogan VK, Strauss RP, Bangdiwala SI. Racial and ethnic disparities in influenza vaccination among elderly adults. J Gen Intern Med 2005;20:426-31.

33. Fiscella K. Commentary-anatomy of racial disparity in influenza vaccination. Health Serv Res 2005;40: 539-49.

34. Shih YC, Zhao L, Elting LS. Does Medicare coverage of colonoscopy reduce racial/ethnic disparities in cancer screening among the elderly? Health Aff 2006;25:1153-62.

35. Gazmararian JA, Baker DW, Williams MV, et al. Health literacy among Medicare enrollees in a managed care organization. JAMA 1999;281:545-51.

36. Tai-Seale M, McGuire TG, Zhang W. Time allocation in primary care office visits. Health Serv Res 2006; OnlineEarly Articles.doi:10.1111/j.14756773.2006 .00689

37. Fiscella K, Williams DR. Health disparities based on socioeconomic inequities: implications for urban health care. Acad Med 2004;79:1139-47.

38. Schillinger D, Piette J, Grumbach K, et al. Closing the loop: physician communication with diabetic patients who have low health literacy. Arch Intern Med 2003;163:83-90.

39. Soumerai SB, Pierre-Jacques M, Zhang F, et al. Cost-related medication nonadherence among elderly and disabled Medicare beneficiaries: a national survey 1 year before the Medicare drug benefit. Arch Intern Med 2006;166:1829-35.

40. Glasgow RE, Orleans CT, Wagner EH. Does the chronic care model serve also as a template for improving prevention?. Milbank Q 2001;79:579-612.

41. McKenna VB, Sager A, Gunn JE, Tormey P, Barry MA. Immunization registries: costs and savings. Public Health Rep 2002;117:386-92.

42. Rodewald LE, Szilagyi PG, Humiston SG, Barth R, Kraus R, Raubertas RF. A randomized study of tracking with outreach and provider prompting to 
improve immunization coverage and primary care. Pediatrics 1999;103:31-8.

43. Jandorf L, Gutierrez Y, Lopez J, Christie J, Itzkowitz $\mathrm{SH}$. Use of a patient navigator to increase colorectal cancer screening in an urban neighborhood health clinic. J Urban Health 2005;82:216-24.

44. Dietrich AJ, Tobin JN, Cassells A, et al. Telephone care management to improve cancer screening among low-income women: a randomized, controlled trial. Ann Intern Med 2006;144:563-71.

45. Worrall A, Rea JN, Ben-Shlomo Y. Counting the cost of social disadvantage in primary care: retrospective analysis of patient data. BMJ 1997;314:38-42.
46. Casalino LP, Elster A. Will pay-for-performance and quality reporting affect health care disparities? Health Aff 2007;26(3):w405-14.

47. Agrawal S, Bhupinderjit A, Bhutani MS, et al. Colorectal cancer in African Americans. Am J Gastroenterol 2005;100:515-23.

48. Benard VB, Lee NC, Piper M, Richardson L. Racespecific results of Papanicolaou testing and the rate of cervical neoplasia in the National Breast and Cervical Cancer Early Detection Program, 1991-1998 (United States). Cancer Causes Control 2001;12: 61-8. 